\title{
Storytelling as an Aid in Promoting Oral Proficiency of Grade Eleven Students From Teachers' Perspectives in Tulkarm District
}

\author{
Ziyad Ahmed Iraheem Tanni \\ Al-Quds Open University, Tulkarm, Palestine
}

\author{
Ahmed Awad Amin Mahmoud Raba' \\ An-Najah University, Nablus, Palestine
}

\begin{abstract}
This study aimed to investigate the role of storytelling in promoting students' oral proficiency from the teachers' perspectives in Tulkarm District. To achieve this aim, the researchers prepared a 30-item questionnaire which was distributed among 50 male and female governmental school teachers, who teach English for Palestine for Grade 11 in Tulkarm District, during the second semester of the scholastic year 2011-2012. The researchers used different statistical procedures which fit the collected data. The results of the study revealed that most of English teachers agreed that storytelling plays a remarkable role in promoting the 11th grade students' oral proficiency in the classroom. In the light of these results, the researchers recommended using storytelling to motivate students to speak in the classroom, and to conduct studies on digital storytelling as an aid in promoting oral proficiency.
\end{abstract}

Keywords: storytelling, oral proficiency, teachers' perspectives

\section{Introduction and Theoretical Background}

One of the major challenges that language teachers face, as Chaney and Burk (1988) stated, is promoting oral language proficiency. Additionally, both language teachers and learners often consider speaking as the most difficult aspect of learning a language. They defined speaking as "the process of building and sharing meaning through the use of verbal and non-verbal symbols, in a variety of contexts".

There are many reasons for integrating oral language instruction in school settings. According to Cregan (1998):

Oral language is the child's first, most important, and most frequently used structured medium of communication. It is the primary means through which each individual child will be enabled to structure, to evaluate, to describe and to control his/her experience. In addition, and most significantly, oral language is the primary mediator of culture, the way in which children locate themselves in the world, and define themselves with it and within it. (p. 7)

According to Kayi (2006), teaching speaking constitutes an important part of second language learning since the ability to communicate in a second language fluently contributes to the learner's success in school as well as in every phase of his life. Therefore, language teachers should pay attention to teaching speaking.

It has been said that storytelling is one of the earliest forms of folk art. Storytelling probably first consisted

Ziyad Ahmed Iraheem Tanni, assistant professor, Ph.D. in TEFL, Tulkarm Branch, Al-Quds Open University, Tulkarm, Palestine.

Ahmed Awad Amin Mahmoud Raba', associate professor, Ph.D. in TEFL, Faculty of Education and Teacher Training and Higher Education, An-Najah University, Nablus, Palestine. 
of simple chants that praised the dawn, expressed the joy of being alive, and were used to ease the drudgery and boredom of laborious tasks. Later, storytelling became the community entertainer by combining their stories with poetry, music, and dance. Storytelling, in the middle ages, was expanded into the art of the traveling troubadover who journeyed across the land. They were welcomed in castle, court, and marketplace. They gathered the news, conveyed the best tales and were expected to know the favorites in each region. The invention of moveable type and the development of the print publishing business led to the decline of storytelling (Ellis, 1997).

Recently, a renewed interest in the art of storytelling has appeared. One aspect of this interest is the emergence of professional storytellers who travel around the United States and Canada. Storytelling conferences and festivals attracted wide audience. Nowadays, in formal storytelling, the teller prepares a story to present to his listeners. Some are from his own imagination; others are gathered, and sometimes are adapted from books and other storytellers. Folklore stories such as myths, epics, legends, and fables are still widely preferred (Stone, 1998; Wilson, 2005; Sobol, 2008; Soleimani, \& Akbari, 2013).

According to Pedersen (1995), storytelling is the original form of teaching, and there are still societies in which it is the only form of teaching. Despite the attempts that have been made to imitate or update it, for example, the electronic storytelling of television, live oral storytelling will be never old fashion strategy of teaching. A simple narrative will always be the cornerstone of the art of teaching. Storytelling in the classroom provides a method that every student can connect to, according to Rosen (1991) who stated, "our memories make storytellers of us all" (p. 53).

As a learning tool, storytelling can encourage students to explore their unique expressiveness and can heighten a student's ability to communicate thoughts and feelings in an articulate, lucid manner. Since people began to communicate with each other, "tell me a story" has been a request to both children and adults. Storytelling is one person telling others of something. The story can be a real event or it can be made up. Storytelling is often a part of our everyday conversation.

As Baker and Greene (1977) asserted: "storytelling brings to the listeners heightened awareness—a sense of wonder of mystery, of reference for life. This nurturing of the spirit-self comes first. It is primary purpose of storytelling, and all other uses and effects are secondary" (p. 17).

\section{Problem of the Study}

Teachers and supervisors in schools are in full agreement that students in Palestinian schools suffer great difficulty in expressing themselves. Using storytelling in English classes is said to lessen this difficulty by increasing student's willingness and desire to make use of storytelling to develop their oral proficiency. Hence, this study investigated the role of storytelling in promoting students' oral proficiency.

\section{Aims of the Study}

This study aimed to find out the effectiveness of using storytelling as an aid of promoting student's oral proficiency of Grade 11 students from teachers' perspectives in Tulkarm District.

\section{Significance of the Study}

The importance of this study emerged from the fact that it provides the necessary information for showing 
the effectiveness of using storytelling in teaching English in general and speaking in particular.

\section{Questions of the Study}

This study tried to give reasonable answers to the following questions:

Are there any significant differences at $(\alpha \leq .05)$ in the role of storytelling in promoting oral proficiency of Grade 11 Students from the teachers' perspectives due to gender variable?

Are there any significant differences at $(\alpha \leq .05)$ in the role of storytelling in promoting oral proficiency of Grade 11 Students from the teachers' perspectives due to qualification variable?

Are there any significant differences at $(\alpha \leq .05)$ in the role of storytelling in promoting oral proficiency of Grade 11 Students from the teachers' perspectives due to experience variable?

\section{Hypotheses of the Study}

There are no statistical significant differences at $(\alpha \leq .05)$ in the role of storytelling in promoting oral proficiency of Grade 11 Students from the teachers' perspectives due to gender variable.

There are no significant statistical differences at $(\alpha \leq .05)$ in the role of storytelling in promoting oral proficiency of Grade 11 Students from the teachers' perspectives due to qualification variable.

There are no significant statistical differences at $(\alpha \leq .05)$ in the role of storytelling in promoting oral proficiency of Grade 11 Students from the teachers' perspectives due to experience variable.

\section{Limitations of the Study}

This study was limited to 50 male and female teachers who were randomly chosen from Governmental schools in Tulkarm District. The chosen teachers were teaching English to Grade 11 during the second semester of the scholastic year 2011-1012.

\section{Definition of Terms}

Storytelling is:

An art form by which a storyteller transmits both mental and emotional images to an audience using spoken word, gestures, sign language, and matches the needs of both environment and audience. It reflects all cultures and literature and is used for "educational, recreational, historic, folkloric, entertainment and therapeutic purposes. (Livo \& Rietz, 1986, p. 6)

Oral proficiency includes the ability to communicate verbally in a functional and accurate way in the target language. A high degree of oral proficiency implies having the ability to apply the linguistic knowledge to new contexts (topics) and situations (Omaggio, 1986).

\section{Reviewing the Related Literature}

By reviewing the related literature, the researchers found out that all the previous research that studied the role of using storytelling in teaching agreed on its usefulness in teaching in general, and in teaching English language in particular. The researchers present summaries of some of these studies as follows:

In a study conducted by Cliatt and Shaw (1988), the researchers reported that storytelling not only helped participants enhance the language and logic skills of the children, but also resulted in the development of positive 
attitudes towards instruction. As a result, they concluded that the connection between literacy development in children and storytelling was well established.

Strickland and Morrow (1989), who conducted a study entitled "Oral Language Development: Children as Storytellers", argued that although storytelling is initially difficult for young children, it is a very beneficial activity to their oral language development. They demonstrated that through scaffolding and the careful structuring of storytelling activities, storytelling can be invaluable and successful component of a language curriculum for young children.

Meyer (1995) conducted a study entitled "Stories to Teach and Teaching to Story: The Use of Narrative in Learning to Teach". The researcher offers seven stories about one teacher's preschool and elementary school children to demonstrate that it is from their students that teachers learn to be better teachers.

In a study entitled "Storytelling in Teaching Children How to Speak", Malkina (1995) stressed that stories are an effective technique for early language learning. She demonstrated that storytelling should be seen as an essential part of early language teaching as it provides a child with a rich and adaptable experience. She added that storytelling helps children to acquire cultural literacy that makes their language learning meaningful.

Wallace (2000) noted that, "the phenomenon of storytelling actually becomes a common language that facilitates meaningful communication; we can hear and understand each other's stories because we can usually recognize ourselves in the stories of others-no matter how varied our cultural backgrounds" (p. 436).

In a meta-analysis of eight studies regarding the use of storytelling as a pedagogical strategy, Mello (2001) found that storytelling enhances fluency and improves self-awareness, visual imagery, and cultural knowledge. Her analysis included information from pre and post interviews with participants, student's retellings, measures of fluency, and writing samples from the students.

In a study entitled "Storytelling as a Constructive Model for Developing Language and Literacy", Palmer, Hershberger, and Koch (2001) presented observations of two community-sponsored summer programs in which storytelling was used as a vehicle for expanding children's existing oral language and developing their literacy abilities. They also described how children first participated as attentive listeners to the professional storytellers, then became creative retellers, and finally used story mapping. They found that the children quickly adapted to stories as a vehicle for active learning.

Stoyle (2003) said that stories can link not only between the world of classroom and home but also between the classroom and beyond. Stories provide a common thread that can help unite cultures and provide a bridge across the cultural gap. Among the values that storytelling instills in its participants as stated by Margaret Read Macdonald in The Storytellers Start-Up Book, is that "it hones our literary and imaginative skills. We improve our ability to listen, speak, imagine, compose phrases and create stories" (Macdonald, 1993, p. 101).

Isbell, Sobol, Linduar, and Lawrence (2004) studied the impact of storytelling and reading stories on the development of language and comprehension of three to five year old children. Although the participants were divided into two groups, the same 20 stories were heard by all students. The first group had the stories told. While the second group listened to the stories as they were read from a book. The results showed that both groups benefited from the instruction. The group who heard the stories told experienced greater comprehension as demonstrated in their retelling of the stories. The storytelling group was more able to identify the setting, the morale of the story, and the characters from the stories. They also found that storytellers tend to use more 
repetition, sounds, and gestures than a person merely reading a story. They added that storytelling is considered as an effective strategy for developing listening skills and keeping students engaged.

Dugan (1997) demonstrated that storytelling utilizes the social element of language since it relies on both the listener and the teller. Researchers have found that literacy instruction is the most effective when developed through social interaction and collaboration with others. Remenyi (2005) reported that storytelling is a fundamental method for sharing knowledge among people as it allows participants to be transported to another time and place.

Hoberman $(2004,2005, \& 2007)$ supported the use of short stories in dialogue form. She argued that these stories, including fairy tales, scary stories, stories from the 21 st century and more, are great, and perfect for the students' first storytelling experience because they are very short, simple, fun, and can be told with a partner.

Cheng (2007) conducted a study entitled "The Effects of English Storytelling on Learning Attitudes and English Proficiency of the Sixth-Grade Students”. The purpose of this study was to explore the effects of English storytelling on the sixth-grade students' learning attitudes and English proficiency. The results showed that storytelling could help in teaching English to the EFL (English as a Foreign Language) sixth graders. It also revealed that storytelling impacted some students' knowledge as well as their learning attitudes. The study showed that student's learning attitudes had affected their English proficiency after storytelling, and so it was concluded that storytelling was an especially combination of teaching and learning.

Eder's (2007) examination of Navajo storytelling practices revealed that in the Navajo culture, stories are used to help construct important concepts and as the instrument through which knowledge is passed from one generation to the next. She found that the stories, which were primarily told by the elders, focus on key concepts such as respect and moral responsibility to oneself, others, and the environment. She noted that families who have used stories to help their children learn important life lessons are considered to have raised their children properly.

According to Haven and Ducey (2007) storytelling can be used as an effective means to increase early literacy and promote reading comprehension skills through active engagement with the stories which helps students develop of a sense of story. Miller and Pennycuff (2008) stated that using storytelling in the classroom is one way to address literacy development by improving oral language, reading comprehension, and writing. Because of the interrelated nature of the processes involved in reading and writing, storytelling is an effective pedagogical strategy that can be woven into instruction to increase students' competencies in all areas.

Some researchers have focused on the practical application of storytelling as a pedagogical strategy to build reading comprehension. Black (2008), offered techniques for incorporating storytelling into the literature the students are reading in the classroom. Students are asked to read at least five different stories and find one that they would like to tell. After reading the story, the student tries to tell the story to a partner. Following the retelling, students go back to the text to be sure that the important details are included. Students can also work with partners to retell the story using only six sentences - two each for the beginning, middle, and end. Following the six sentence version, students can try to tell the story using only three sentences-one sentence for the beginning, one for the middle, and one for the end. With a partner, the students share their stories. The listening partner offers positive feedback to the storyteller and then they are asked to offer one suggestion that might make the storytelling even better. The storytellers are then ready to begin telling their stories to the class. In her work, 
Black has witnessed a growing enthusiasm for storytelling as she helps students experiment to find just the right voice, facial expressions, and gestures to tell a story.

McGuire(1985) mentioned the specific educational and social benefits of storytelling from a child's point of view. Some of the values he touched upon are: helping a child recognize patterns in language, stimulating a child's powers of creativity, providing a child with problem solving and decision making activities, strengthening a child's capacity to form objective, rational, and practical applications, assisting a child to develop skills in dialogue and cooperative interpersonal behavior. It also familiarizes and introduces a child to symbols, and traditions of different cultural heritages shared among the people around them. He stated that there are tremendous gains to be made through storytelling as a strategy to increase the oral language of second language learners in particular.

Archibald (2008) said that stories mirror human thought as humans think in narrative structures and most often remember facts in story form. Facts can be understood as smaller versions of a larger story thus storytelling can supplement analytical thinking. Because storytelling requires auditory and visual senses from listeners, one can learn to organize their mental representation of a story, recognize structure of language, and express his/her thoughts.

According to Andrews and Hull (2009), learning is the most effective when it takes place in social environments that provide authentic social cues about how knowledge is to be applied. In this regard, they demonstrated that stories provide a tool to transfer knowledge in a social context.

Cajete, Eder, and Holyan (2010) overemphasized the role of stories saying that when the story is told using a combination of oral narrative, music, rock art, and dance, it brings understanding and meaning of human existence through remembrance and enactment of stories. People have used the carved trunks of living trees and ephemeral media (such as sand and leaves) to record stories in pictures or with writing. Complex forms of tattooing may also represent stories, with information about genealogy, affiliation, and social status.

Nurussaniyah (2010) stated that storytelling is an effective strategy to help students obtain oral language proficiency. In instructed language learning situations where the exposure to English is only in school, stories and storytelling serve the purpose of not simply promoting listening skills, but also develop oral language proficiency. She added that children may move from being mere listeners of stories to beginning storytellers in an interactive way. She argued that storytelling can be used by using four skills depending on the situation of students and atmosphere of place.

Atta-Alla (2012) said that storytelling is a means for sharing and interpreting experiences. Stories are universal in that they can bridge cultural, linguistic, and age-related divides. Storytelling can be adaptive for all ages leaving out notion of age segregation. Storytelling can be used as a method to teach ethics, values, and cultural norms and differences.

\section{Methodology}

Descriptive statistical analysis was used to achieve the main purpose of the study and to answer the study questions. 


\section{Population of the Study}

The population of the study consisted of 82 male and female teachers of English who teach Grade 11 in 52 schools in Tulkarm District in the second semester of the scholastic year 2011-2012.

\section{Sample of the Study}

The sample of the study which formed 60.9 of the whole population consisted of 52 teachers. The teachers were chosen randomly from 25 schools. It is worth mentioning here that the number of teachers in these schools varies from one teacher to three and in two of them the number was four. Tables 1, 2, and 3 below describe the sample of the study according to the independent variables of the study.

\section{Gender Variable}

Table 1

Sample Distribution According to Gender

\begin{tabular}{lll}
\hline Sex & Frequency & Percentage \\
\hline Male & 23 & $46 \%$ \\
Female & 27 & $54 \%$ \\
Total & 50 & $100 \%$ \\
\hline
\end{tabular}

\section{Qualification Variable}

Table 2

Sample Distribution According to Qualification

\begin{tabular}{lll}
\hline Qualification & Frequency & Percentage \\
\hline Diploma & 2 & $4.0 \%$ \\
B.A & 39 & $78.0 \%$ \\
M.A & 9 & $18.0 \%$ \\
Total & 50 & $100 \%$ \\
\hline
\end{tabular}

\section{Experience Variable}

Table 3

Sample Distribution According to Experience

\begin{tabular}{lll}
\hline Years of Experience & Frequency & Percentage \\
\hline $1-5$ years & 3 & $6.0 \%$ \\
$5-10$ years or more & 47 & 94.0 \\
Total & 50 & $100 \%$ \\
\hline
\end{tabular}

\section{Instrument of the Study}

A five-point Likert scale questionnaire was used to measure teachers' perspectives towards using storytelling as an aid in promoting oral proficiency of Grade 11 students. The questionnaire consisted of 30 items.

\section{Validity of the Instrument}

The researchers presented copies of the questionnaire to a jury from the faculty of Education at An-Najah National University and AL-Quds Open University. The jury suggested some modifications which were taken 
into consideration in the new copy of the questionnaire.

\section{Reliability of the Instrument}

To test the reliability of the questionnaire, Alpha formula (Cranach Alpha) was used to determine the homogeneity of the level of the instrument as a whole. Results showed that the range of reliability of the questionnaire was 0.87 . This value was considered to be suitable for the purpose of this study.

\section{Procedure of the Study}

The researchers used the following procedures during the application of the study:

(1) After establishing the validity and reliability of the questionnaire by consulting specialists in the Faculty of Education who approved the utility of the instrument for conducting the study, the researchers incorporated the amendments suggested by the specialists;

(2) The researchers brought the population of the study from the supervisor of English in the Directorate of Education in Tulkarm;

(3) The researchers chose the sample of the study randomly, which represented 60.9 from the population;

(4) The researchers themselves distributed the copies of the questionnaire. In order to obtain more credible and valid results, the teachers were given freedom to complete the questionnaire either immediately, while the researchers are away, or at home;

(5) The researchers managed to get back all the questionnaires distributed. Then the data were statistically treated.

\section{Statistical Analysis}

In order to analyze the data, the researchers used the Statistical Package for Social Science (SPSS). The following statistics were used:

(1) Means, standard deviation, and percentages;

(2) Independent Samples T-test;

(3) One way ANOVA.

For the purpose of interpreting the results of the study, the following percentages and ranks were used:

Table 4

Likert's Five-Point Scale

\begin{tabular}{ll}
\hline Percentage & Ranks \\
\hline $80 \%$ and more & Very good \\
$79.9 \%-70 \%$ & Good \\
$69.9 \%-60 \%$ & Medium \\
$59.9 \%-50 \%$ & Poor \\
Less than $50 \%$ & Very poor \\
\hline
\end{tabular}

\section{Results of the Study}

The data of the study were statistically analyzed and the results were as follows: 
Table 5

Means, Percentages, Standard Deviation, and the Degree of Significance for Each Item

\begin{tabular}{|c|c|c|c|c|c|c|}
\hline Scale & $\%$ & St. Dv. & Mean & The role of in promoting students' oral proficiency & No. & Sequential No. \\
\hline Very good & 90.00 & 0.54 & 4.50 & Contributes to a relaxed classroom atmosphere & 30 & 1 \\
\hline Very good & 87.60 & 0.57 & 4.38 & Introduces and expands oral language & 4 & 2 \\
\hline Very good & 86.80 & 0.56 & 4.34 & Stimulates fluency & 1 & 3 \\
\hline Very good & 85.20 & 0.60 & 4.26 & Improves students' communicative performance & 5 & 4 \\
\hline Very good & 84.00 & 0.76 & 4.20 & Stimulates imagination & 9 & 5 \\
\hline \multirow[t]{2}{*}{ Very good } & 83.20 & 0.71 & 4.16 & Encourages shy students to speak & 2 & 6 \\
\hline & 81.20 & 0.77 & 4.06 & Creates more attractive learning atmosphere & 24 & 7 \\
\hline Very good & 81.20 & 0.65 & 4.06 & Attracts listeners and promotes communication & 27 & 8 \\
\hline \multirow[t]{2}{*}{ Very good } & 81.20 & 0.77 & 4.06 & Develops concentration and attention skills & 12 & 9 \\
\hline & 80.80 & 0.83 & 4.04 & Encourages students to talk and discuss with each other & 14 & 10 \\
\hline Very good & 80.80 & 0.70 & 4.04 & $\begin{array}{l}\text { Helps students to be more self-confident to express themselves } \\
\text { spontaneously and creatively }\end{array}$ & 15 & 11 \\
\hline Very good & 80.40 & 0.68 & 4.02 & Fosters vocabulary and structure development & 10 & 12 \\
\hline Very good & 80.40 & 0.80 & 4.02 & Provides a real-life situation & 6 & 13 \\
\hline Good & 79.20 & 0.75 & 3.96 & Heightens students' ability to communicate thoughts and feelings & 19 & 14 \\
\hline Good & 79.20 & 0.97 & 3.96 & Provides intensive and meaningful language practice & 8 & 15 \\
\hline Good & 77.60 & 0.92 & 3.88 & Gives students opportunities to interact with the target language & 3 & 16 \\
\hline Good & 77.60 & 0.85 & 3.88 & Develops critical and active listening skills & 11 & 17 \\
\hline Good & 77.20 & 0.76 & 3.86 & Facilitates recall of content and facts & 7 & 18 \\
\hline Good & 77.20 & 0.76 & 3.86 & Helps information illustration and abstract concepts explanation & 28 & 19 \\
\hline Good & 76.40 & 0.87 & 3.82 & Improves students' pronunciation, stress and intonation & 25 & 20 \\
\hline Good & 76.40 & 0.87 & 3.82 & $\begin{array}{l}\text { Encourages children create their own stories and later write and } \\
\text { illustrate stories }\end{array}$ & 26 & 21 \\
\hline Good & 76.00 & 0.90 & 3.80 & $\begin{array}{l}\text { Makes language learning meaningful as it helps students acquire } \\
\text { cultural literacy }\end{array}$ & 17 & 22 \\
\hline Good & 75.60 & 0.79 & 3.78 & Promotes whole class participation. & 16 & 23 \\
\hline Good & 75.60 & 0.91 & 3.78 & promotes students' learning attitudes & 23 & 24 \\
\hline Good & 74.80 & 0.90 & 3.74 & Creates reasonable responses even to reluctant students & 29 & 25 \\
\hline Good & 74.40 & 0.76 & 3.72 & $\begin{array}{l}\text { Improves students' ability of story structure, comprehension, and } \\
\text { oral language complexity }\end{array}$ & 18 & 26 \\
\hline Good & 73.60 & 0.71 & 3.68 & Encourages students to explore their unique expressiveness. & 20 & 27 \\
\hline Good & 73.60 & 1.06 & 3.68 & Assists in writing development & 13 & 28 \\
\hline Good & 72.80 & 0.96 & 3.64 & Helps students develop higher-level of thinking & 22 & 29 \\
\hline Good & 70.80 & 0.76 & 3.54 & Is a motivational tool that enhances instruction & 21 & 30 \\
\hline Good & 79 & 0.36 & 3.95 & Total degree & & \\
\hline
\end{tabular}

It is clear from Table 5 above that the degree of significance was very good on items $(1,2,4,5,6,9,10,12$, $14,15,24,27$, and 30 ) where the percentage of response reached $80 \%$ and above. On the other hand, the degree of significance was good on items $(3,7,8,11,13,16,17,18,19,20,21,22,23,25,26,28$, and 29). As for the total degree for the storytelling as an aid in promoting 11th grade students' oral proficiency, it was good where the percentage for the response was $79 \%$. This means that a great portion of teachers do believe that using storytelling aids in promoting their students oral proficiency.

In order to test the first hypothesis which states that: "there are no significant statistical differences at $(\alpha \leq$ 0.05 ) for storytelling as an aid in promoting students' oral proficiency due to gender variable”. Independent T-test was used as Table 6 shows. 
Table 6

The Results of the T-Test for Storytelling as an Aid in Promoting 11 th Grade Students' Oral Proficiency Due to Gender

\begin{tabular}{llllll}
\hline \multirow{2}{*}{ Significance } & \multirow{2}{*}{ t-value } & \multicolumn{2}{c}{ Female } & \multicolumn{2}{c}{ Male } \\
& & & \multicolumn{2}{c}{27} & \\
& & Standard deviation & Mean & Standard deviation & Mean \\
\hline 0.46 & 0.75 & 0.31 & 3.99 & 0.42 & 3.91 \\
\hline
\end{tabular}

The above table shows that the value of $t$ was 0.75 and this value is less than the value of $t$ for the DF (2.021) which means that there were no significant differences at $(\alpha \leq 0.05)$ from the teachers' perspectives due to gender. This means that the teacher's gender does not affect his/her perspective towards the role of storytelling in promoting oral proficiency. Then, the first null hypothesis is valid.

To answer the second question of the study. "Are there any significant statistical differences at $(\alpha \leq 0.05)$ from the teachers' perspectives due to experience?", T-test was used as Table 7 shows.

Table 7

T-Test Results That Show the Differences in the Degree of Evaluation by the Teachers in Regard to Experience

\begin{tabular}{llllll}
\hline \multirow{2}{*}{ Significance } & \multirow{3}{*}{ t-value } & \multicolumn{2}{c}{ From 5-10 years and more } & \multicolumn{2}{c}{$1-5$ years } \\
\cline { 3 - 6 } & & Standard deviation & Mean & Standard deviation & Mean \\
\hline 0.29 & 1.07 & 0.37 & 3.94 & 0.19 & 4.71 \\
\hline
\end{tabular}

It is clear from the above table that the $t$ value is (1.07) which is less than the value of $t$ for the DF. This means that there were no significant differences at $(\alpha \leq 0.05)$ from the teachers' perspectives due to experience. This means that the teacher's experience does not affect his/ her perspective towards the role of storytelling in promoting oral proficiency, and consequently the second null hypothesis is valid.

To answer the third question of the study: "Are there any significant statistical differences at $(\alpha \leq 0.05)$ from the teachers' perspectives due to qualification?", ANOVA test was used as Tables 8 and 9 below show.

Table 8

The Means Results That Show the Differences in the Degree of Evaluation by the Teachers in Regard to Qualification

\begin{tabular}{llll}
\hline \multirow{2}{*}{ Qualification } & Diploma & Bachelor & Master's \\
& 2 & 39 & 9 \\
\hline Means & 3.68 & 3.97 & 3.94 \\
\hline
\end{tabular}

Table 9

One Way ANOVA Results That Show the Differences in the Degree of Evaluation by the Teachers in Regard to Qualification

\begin{tabular}{|c|c|c|c|c|c|}
\hline Significance & $\mathrm{F}$ & Mean square & Sum of squares & DF & Source of variance \\
\hline & & 0.077 & 0.155 & 2 & Between groups \\
\hline 0.56 & 0.58 & 0.133 & 6.250 & 48 & $\begin{array}{l}\text { Within groups } \\
\text { total }\end{array}$ \\
\hline
\end{tabular}

This table shows that the value of $\mathrm{F}$ which was 0.58 is less than $\mathrm{t}$-value, which means that there were no significant statistical differences at $(\alpha \leq 0.05)$ due to qualification variable. This indicates that the teacher's 
qualification does not affect his/her perspective towards the role of storytelling in promoting oral proficiency, and consequently the third null hypothesis is valid.

\section{Conclusion}

Based on the analysis of data, the following brief final conclusions were reached:

Teachers have positive perspectives towards using storytelling as an aid in promoting the oral proficiency of their students.

The teacher's gender does not affect his/her perspective towards using storytelling as an aid in promoting oral proficiency.

The teacher's experience does not affect his/her perspective towards using storytelling as an aid in promoting oral proficiency.

The teacher's qualification does not affect his/her perspective towards using storytelling as an aid in promoting oral proficiency.

From these conclusions, storytelling is very effective regardless of all the independent variables included in this research which could be a strong invitation for other researchers to prove or refute the above-mentioned conclusions.

\section{Recommendations}

Based on the conclusions made, the following recommendations are forwarded:

The Ministry of Education is recommended to train teachers on the different methods of storytelling.

Teachers are recommended to use storytelling as an aid in promoting their students' oral proficiency along with other language skills.

Researchers are recommended to conduct studies on how can storytelling be an aid oral proficiency in embedded or on-line courses.

Researchers are recommended to conduct studies on the obstacles of using storytelling as an aid in promoting oral proficiency as perceived by teachers.

\section{References}

Alvey, R. G. (1974). The historical development of organized storytelling to children in the United States (Ph.D. dissertation, University of Pennsylvania).

Andrews, D., \& Hull, D. (2009). Storytelling as an instructional method: Descriptions and research question. The Interdisciplinary Journal of Problem-Based Learning, 2(3), 6-23.

Andrews, J. A. (2008). Indigenous story work: Educating the heart, mind, body and spirit. Vancouver, British Columbia: The University of British Columbia Press.

Atta-Alla, M. N. (2012). Integrating language skills through storytelling. English Language Teaching Journal, 5(12), 1-13.

Baker, A., \& Greene, E. (1977). Storytelling: Art and technique. New York: R. R. Bowker.

Cajete, G., Eder, D., \& Holyan, R. (2010). Life lessons through storytelling: Children's exploration of ethics. Bloomington: Indiana UP.

Chaney, A. L., \& Burk, T. L. (1998). Teaching oral communication in grades K-8. Boston: Allyn and Bacon.

Cliatt, M., \& Shaw, J. (1988). The story time exchange: Ways to enhance it. Childhood Education, 64(5), 293-298. (ERIC Document Reproduction Service No. EJ373896)

Cregan, A. (1998). Developing language and literacy: The role of the teacher. In G. Shiel and U. Ní Dhálaigh (Eds.), Developing language and literacy: The role of the teacher (pp. 3-15). Dublin: Reading Association of Ireland. 
Dugan, J. (1997). Transactional literature discussions: Engaging students in the appreciation and understanding of literature. Reading Teacher, 51(2), 86-96.

Eder, D. J. (2007). Bringing Navajo storytelling practices into schools: The importance of maintaining cultural integrity. Anthropology and Education Quarterly, 38(3), 278-296.

Ellis, B. F. (1997). Why tell stories? Storytelling Magazine, 9,(21), 21-23.

Hoberman, M. A. (2004). You read to me, I'll read to you: Very short fairy tales to read together. New York: Little, Brown.

Hoberman, M. A. (2005). You read to me, I'll read to you: Very short mother goose tales to read together. New York: Little, Brown. Hoberman, M. A. (2007). You read to me, I'll read to you: Very short scary tales to read together. New York: Little, Brown.

Isbell, R., Sobol, J., Linduar, L., \& Lowrance, A. (2004). The effects of storytelling and story reading on the oral language complexity and story comprehension of young children. Early Childhood Education Journal, 32(3), 36-43.

Kayi, H. (2006). Teaching speaking : Activities to promote speaking in a second language. Retrieved from http://unr. edu/homepage hayriyek kayih@unr.nevadaedu

Livo, N. J., \& Rietz, S. A. (1986). Storytelling: Process \& practice. Littleton, CO: Libraries Unlimited, Inc..

MacDonald, M. R. (1993). The storytellers start-up book. Little Rock: August House.

Maguire, J. (1985). Creative storytelling. New York: McGraw Hill Book Company.

Malkina, N. (1995). Storytelling in teaching children to speak. Exchange English Teaching Forum, 33(1), 38-40.

Mello, R. (2001). Building bridges: How storytelling influences teacher and student relationship. (ERIC Document Reproduction Service No. ED457088)

Meyer, R. J. (1995). Stories to teach and teaching to story: The use of narrative in learning to teach. Language Arts, 72(4), $276-286$.

Miller, S., \& Pennycuff, L. (2008). The power of story: Using storytelling to improve literacy learning. Journal of Cross-Disciplinary Perspectives in Education, 1(1), 36-43.

Nurussaniyah, H. (2010). Teaching by using story telling. Method. English education program (Teaching and Education Faculty, Ibn Khaldun University, Bogor, Indonesia).

Omaggio, A. (1986). Teaching language in context: Proficiency oriented instruction. Boston, MA: Heinle and Heinle Publishers.

Palmer, B. C., Harshbarger, S. J., \& Koch, C. A. (2001). Storytelling as a constructive model for developing language and literacy. Journal of Poetry Therapy, 14(4), 199-212.

Pederson, E. M. (1995). Storytelling and the art of teaching. Forum, 33(1).

Rosen, B. (1991). Shapers and publishers: Teachers as storytellers. London: Mary Glasgow Publications.

Sobol, J. D. (2008). Contemporary storytelling: Revived traditional art and protean social agent. Storytelling, Self, Society, 4 , 122-33.

Stone, K. (1998). Burning brightly: New lights on old tales told today. Peterborough, Ontario, Canada: Broadview Press.

Stoyle, P. (2003). Storytelling-benefits and tips. British Council, Jordan: A Workshop.

Soleimani, H., \& Akbari, M. (2013). The effect of storytelling on children's learning English vocabulary. International Research Journal of Applied and Basic Sciences, 5(1), 104-113.

Wallace, C. (2000). Storytelling: Reclaiming an age-old wisdom for the composition classroom. Teaching English in the Two-Year College, 27(4), 434-439.

Wilson, M. (2005). Storytelling and theater: Contemporary storytellers and their art. London: Palgrave.

\section{Appendix \\ Part I}

This questionnaire aims to collect data necessary entitled "Storytelling as an Aid in Promoting Oral Proficiency of Grade Eleven Students From Teachers' Perspective in Tulkarm District”.

Please go through the following questionnaire and put $(\mathrm{X})$ in the place that represents your opinion. Please note that the results will be used for educational purposes.

The first part includes personal information, but the second part includes the items of the questionnaire.

\section{Part 1}

Personal information

Qualification Diploma $\quad$ BA $\quad$ MA 
School

Sex

Experience

Thanks for cooperation.

The Researchers
Male Female
a. $1-5$ years
b. $5-10$ or more

\section{Part II}

Please go through the following questionnaire and put $(\mathrm{X})$ in the place that represents your opinion.

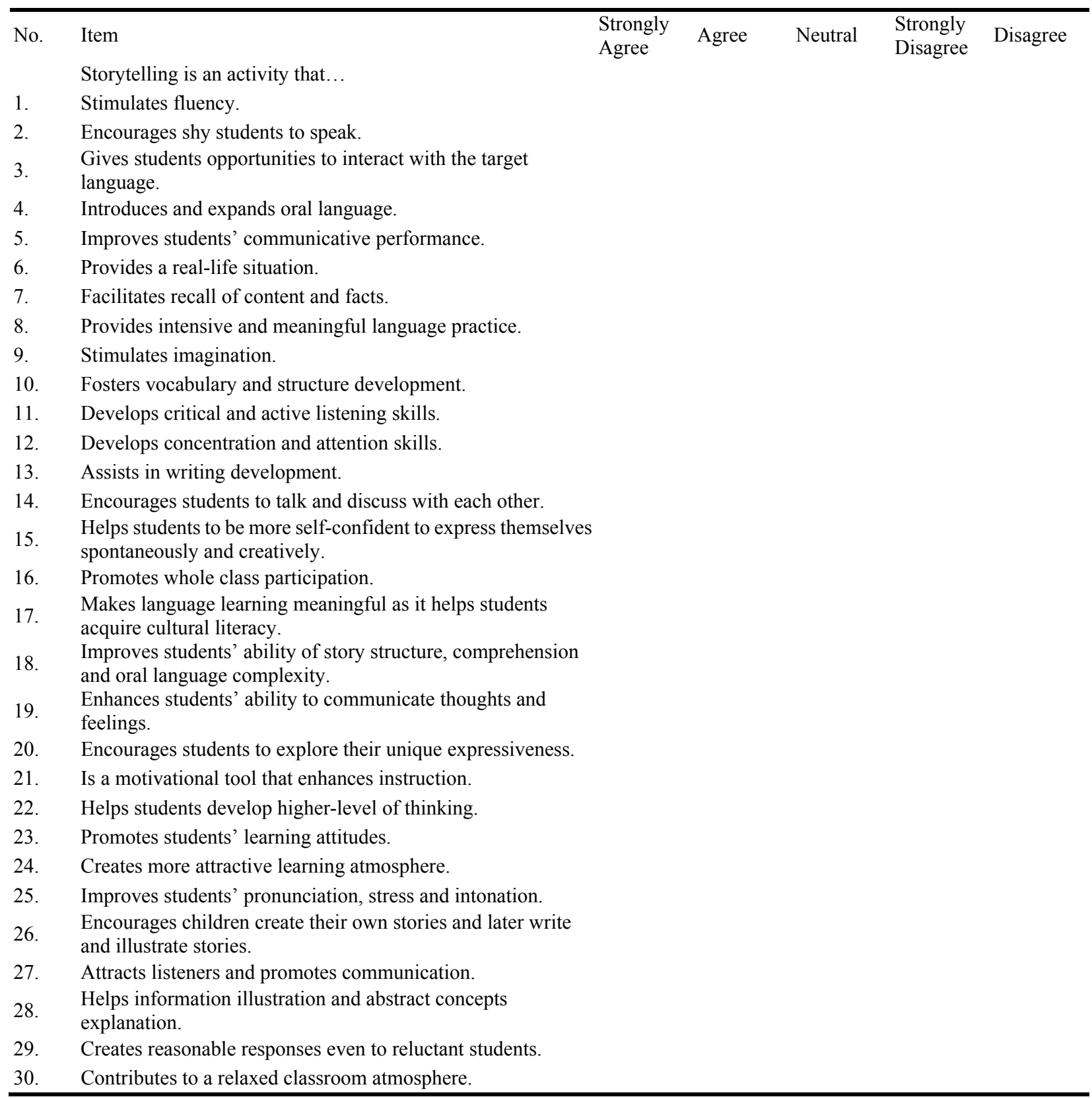

